\title{
Morfoanatomia do eixo vegetativo aéreo de Ayapana triplinervis (Vahl) R.M. King \& H. Rob. (Asteraceae)
}

NERY, M.I.S.*; POTIGUARA, R.C.V.; KIKUCHI, T.Y.S.; GARCIA, T.B.; LINS, A.L.F.A. Museu Paraense Emílio Goeldi, Coordenação de Botânica, Av. Perimetral 1901, Terra Firme, 66077-530, Belém, PA. *Autor para correspondência: isabelnery@bol.com.br

RESUMO: (Morfoanatomia do eixo vegetativo aéreo de Ayapana triplinervis (Vahl) R.M. King \& H. Rob. (Asteraceae). Ayapana triplinervis (Asteraceae) é uma erva medicinal da Amazônia conhecida como "Japana branca" e "Japana roxa" utilizada como tônico, digestivo, antidiarréico dentre outros. Objetivou-se caracterizar neste estudo a morfoanatomia caulinar e foliar de $A$. triplinervis, para corroborar se esta espécie apresenta morfotipos, além de fornecer dados para sua identificação. Amostras foram coletadas no Horto de Plantas Medicinais da Universidade Federal Rural da Amazônia e Embrapa Amazônia Oriental, analisadas morfologicamente e segundo técnicas usuais em anatomia vegetal. O caule é cilíndrico branco ou roxo, com epiderme unisseriada persistente e endoderme com bainha amilífera e estrias de Caspary. As folhas são simples, opostas, triplinervadas, com base atenuada ou decorrente. Possuem estômatos anomocíticos, cera em placas ou granular, glândulas peroladas, mesofilo dorsiventral com feixes colaterais e ductos secretores. A. triplinervis apresentou caracteres morfoanatômicos diferentes entre os tipos branca e roxa, o que possibilita a distinção dos dois morfotipos.

Palavras-chave: Ayapana, glândula perolada, morfotipos, planta medicinal.

ABSTRACT: Morphoanatomy of the vegetative aerial axis of Ayapana triplinervis (Vahl) RM King \& H. Rob. (Asteraceae). Ayapanatriplinervis (Asteraceae), also known as "Japana branca" and "Japana roxa" in Brazil, is a medicinal herb from the Amazon used as tonic, digestive, antidiarrheal, among others. This study aimed to characterize the morphoanatomy of the aerial vegetative axis of $A$. triplinervis to corroborate that this species has morphotypes, in order to provide data for their identification. Samples were collected in the Garden of Medicinal Plants of the Federal Rural University of Amazônia and Embrapa Amazônia Oriental, and they were analyzed morphologically and by the standardtechniques of plant anatomy. The stem is cylindrical, white or purple, with uniseriate epidermis, trichomes and endoderm with starch sheath and Casparian strips. The leaves are simple, opposite, with attenuate or arising basis; they have anomocytic stomata, epicuticular wax plates or granules, pearl glands, dorsiventral mesophyll with collateral vascular bundles and secretory ducts. Ayapana triplinervis showed different morphoanatomical features betweenthe white and purple types, which enablesthe distinction between the two morphotypes.

Keywords: Ayapana, pearl glands, morphotypes, medicinal plant.

\section{INTRODUÇÃO}

A Amazônia brasileira possui um grande número de plantas comumente usadas com fins medicinais, tornando-se, às vezes, a única fonte de remédios para as populações de locais mais distantes dos centros comerciais (Berg, 2010). Asteraceae, representada por 1.535 gêneros e 23.000 espécies (Judd et al., 2009) é considerada uma importante família de interesse terapêutico, em função do vasto número de plantas que são utilizadas na medicina tradicional, dentre as quais, destaca-se Ayapana triplinervis (Vahl) R. M. King \& H. Rob., erva ocorrente na Amazônia, conhecida popularmente como "Japana", "Japana branca", "Japana roxa", "erva de cobra", entre outras denominações (Di Stasi et al., 2002; Souza et al., 2003; Scudeller, 2009).

Estudos farmagnósticos e etnobotânicos de $A$. triplinervis relataram sua eficiência no tratamento de desordens gastrointestinais, afecções da boca, febre, malária e verminoses (Corrêa, 
1984; Longuefosse \& Nossin, 1996; Vigneron et al., 2005; Lans, 2007). Seu princípio ativo devese ao ácido salicílico, inulina, euparina, rinderina, eupatorina, suprinina, equinatina, felandreno e borneol (Albuquerque, 1989; Vieira, 1992). Contudo, Maia et al. (2001) ao analisarem a composição química do óleo essencial extraído do caule e das folhas de $A$. triplinervis observaram que a mesma apresenta divergência química, designando-a por "A" (japana branca) e "B" (japana roxa), além disso observa-se diferenças morfológicas entre seus indivíduos.

Estes fatos, adicionados à escassez de estudos morfoanatômicos de órgãos vegetativos da espécie, reforçam a necessidade de informações referentes à organização estrutural desta espécie, buscando subsídios para sua correta identificação. Diante disto, este trabalho teve como objetivo caracterizar a morfoanatomia do eixo vegetativo aéreo dos tipos "A" branca e "B" roxa de $A$. triplinervis, fornecendo dados que contribuam na identificação botânica desta espécie, assim como, evidenciar os caracteres diagnósticos para os morfotipos.

\section{MATERIAL E MÉTODOS}

Amostras de caules e folhas totalmente expandidas (terceiro ao sexto nó) de Ayapana triplinervis foram coletadas de espécimes cultivados no Horto de Plantas Medicinais da Embrapa Amazônia Oriental - CPATU e da Universidade Federal Rural da Amazônia (UFRA), ambos localizados em Belém, Pará. Foram selecionados quatro espécimes de cada tipo (branca e roxa). $\mathrm{O}$ material testemunho foi depositado no Herbário João Murça Pires com número de registro MG 197.930.

Para a descrição macromorfológica dos órgãos vegetativos, as mensurações foram feitas com auxílio de trena e estereomicroscópio. Para o estudo anatômico, o material foi fixado em $\mathrm{FAA}_{50 / 70}$ (formaldeído + ácido acético glacial + álcool etílico $50 \%, 70 \%, 1: 1: 18 \mathrm{v} / \mathrm{v}$ ) por 24 horas (Johansen, 1940) e FNT (formalina neutra tamponada) por 48 horas (Lillie, 1965).

A epiderme foi dissociada em ácido nítrico $10 \%$ (Johansen 1940) e os fragmentos obtidos foram corados com azul de astra e safranina $1 \%$ (Gerlach, 1969). Segmentos do caule e de folhas foram seccionados a mão, clarificados em hipoclorito de sódio comercial $(1: 1 \mathrm{v} / \mathrm{v})$ e corados com azul de astra e safranina $1 \%$ ou azul de toluidina (O'Brien et al., 1965).

Amostras desidratadas em série etílicabutílica-terciária foram incluídas em parafina e hidroxietilmetacrilato Leica ${ }^{\circledR}$ (Gerrits \& Smid, 1983), respectivamente, e posteriormente seccionadas transversal e longitudinalmente em micrótomo rotativo. As secções do material incluído em parafina $(12-16 \mu \mathrm{m})$ e historresina $(5 \mu \mathrm{m})$, foram coradas com azul astra/safranina hidroalcoólica $2 \%$ e azul de toluidina, respectivamente, sendo as primeiras montadas em resina sintética Permount $₫$. Amostras frescas foram seccionadas a mão para análise em microscopia de fluorescência e tratamentos histoquímicos, utilizando-se solução de lugol para identificar amido e floroglucina acidificada para lignina (Johansen, 1940).

Para o exame ao microscópio eletrônico de varredura (modelo LEO 1450 VP), as amostras foram desidratadas em série etílica (Johansen, 1940), secas em ponto crítico de $\mathrm{CO}_{2}$ (Bozzola \& Russel, 1991) e metalizadas com ouro.

As terminologias utilizadas na descrição morfológica estão de acordo com Hickey (1999) e as fotomicrografias foram obtidas em fotomicroscópio Axiolab Zeiss.

\section{RESULTADOS}

\section{Análise morfológica}

Ayapana triplinervis é uma erva com 40 a $50 \mathrm{~cm}$ de altura, ereta ou semi prostrada. O caule é cilíndrico, piloso em ambos os tipos (Figuras $1 \mathrm{~A} \mathrm{e}$ 1B) com coloração verde, maior número de nós e brotos foliares no tipo "branca" (Figuras 1A e 1C). Enquanto que no tipo roxa o caule apresenta-se com coloração roxa e entrenós curtos (Figuras 1B e 1E). As folhas são simples, herbáceas, sésseis, opostas; limbo $10-12 \mathrm{~cm}$ de comprimento, $1,5-2,5 \mathrm{~cm}$ de largura quando completamente expandido, ovadolanceolado, ápice agudo, margem levemente serreada, base decorrente no tipo branca e atenuada no tipo roxa; nervação acródroma suprabasalbroquidódroma (Figuras $1 \mathrm{D}$ e 1F).

\section{Análise anatômica}

Caule - O caule em estrutura primária dos tipos branca e roxa de $A$. triplinervis, em secção transversal, exibe forma circular, com revestimento epidérmico unisseriado persistente até a fase de desenvolvimento secundário inicial (Figura 2A). A epiderme apresenta cutícula delgada evidenciada em microscopia de autofluorescência (Figuras $2 \mathrm{D}$ e $2 \mathrm{E}$ ); tricomas glandulares (Figura $2 \mathrm{~B}$ ) e não glandulares multicelulares; e células poligonais com vacúolos contendo pigmentação avermelhada nos individuos do tipo roxa. Os tricomas glandulares são constituídos por pedúnculo e célula apical globosa (Figura 2B). Na região cortical ocorrem três a cinco camadas de colênquima angular e diversas camadas de parênquima fundamental, no qual observou-se a presença de espaços intercelulares 


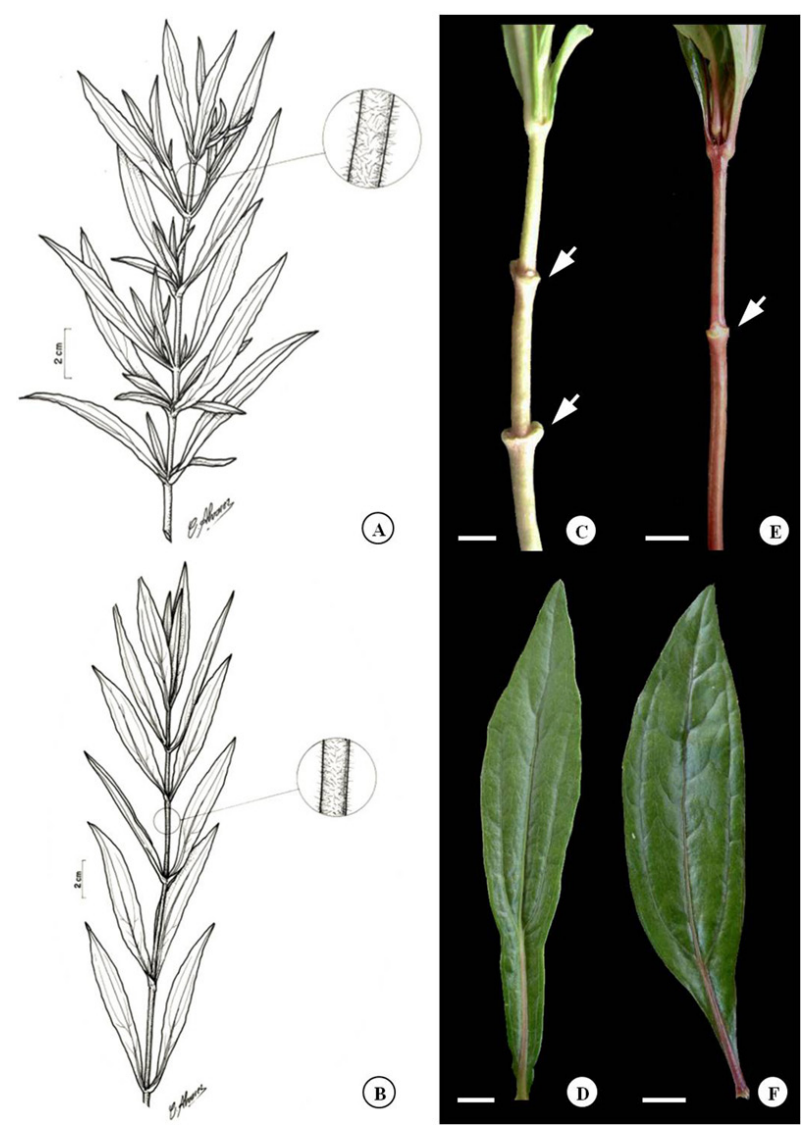

FIGURA 1. Ayapana triplinervis. Tipos Branca (A, C e D) e Roxa (B, E e F). A e B: Ramo destacando caule piloso e diferenças quanto à presença de brotos foliares; C e E: Vista geral dos nós e entrenós do caule (setas); D e F: Vista geral das folhas. Escalas $(C, D$ e $F=0,9 \mathrm{~cm} ; E=1,4 \mathrm{~cm})$.

bem desenvolvidos (Figuras 2A e 2B).

O sistema vascular do caule nos tipos branca e roxa de Ayapana triplinervis é constituído por feixes colaterais, com elementos traqueais dispostos radialmente e floema apresentando calotas de esclerênquima (Figura $2 \mathrm{C}$ ). As células da camada cortical que delimitam o cilindro vascular apresentam espessamentos na parede anticlinal em forma de faixas, caracterizando as estrias de Caspary da endoderme, identificada por autofluorescência (Figura 2F), sendo observada também nesta região uma bainha amilífera (Figura $2 \mathrm{G})$. Com relação à região medular, esta compõe-se de células parenquimáticas poligonais com paredes delgadas e de tamanho relativamente maior em direção ao centro.

Folha - A lâmina foliar dos tipos branca e roxa de Ayapana triplinervis, em vista frontal, apresenta células epidérmicas poligonais de paredes anticlinais retas a levemente sinuosas na face adaxial (Figura 3A), enquanto que na abaxial, estas paredes mostram contorno sinuoso (Figura
3B). Na superfície abaxial do morfotipo "roxa", depósitos de cera epicuticular exibem-se de forma granular (Figura 3C) e em placas na face adaxial (Figura 3C), sendo este último, o padrão encontrado em ambas as superfícies do tipo branca.

As folhas são anfihipoestomáticas, com estômatos anomocíticos (Figura 3B). Em ambas as faces da lâmina foliar foram observados tricomas glandulares e não glandulares. O tipo não glandular é multicelular, unisseriado, recurvado ou não, constituído por uma célula basal, cinco a dez células intermediárias e uma célula apical afilada (Figuras 3E e 3F). Os tricomas glandulares são de dois tipos: digitiforme, constituído por uma série de quatro células (Figura 3G) e globoso, formado por célula basal curta e uma cabeça unicelular (Figuras $3 \mathrm{H} \mathrm{e}$ $3 \mathrm{I})$, sendo este último comumente observado em depressões da superfície epidérmica (Figura 4A).

A lâmina foliar de $A$. triplinervis, em secção transversal, é uniestratificada, constituída por células heterodimensionais e revestida por cutícula delgada. O mesofilo dos espécimes estudados exibe organização dorsiventral, constituído por uma a duas camadas de parênquima paliçádico e seis a oito camadas de células poligonais que formam o lacunoso (Figuras 4A e 4B). A nervura central apresenta formato plano-convexo a biconvexo na porção apical (Figura 4C), biconvexo na região mediana (Figura 4D) e côncavo-convexo na região basal, com duas a cinco camadas de colênquima angular (Figuras 4C e 4D). Na região da margem, em secção transversal, observa-se uma camada de colênquima angular e tecido parenquimático fundamental (Figura 4E). Em todas as regiões da lâmina foliar ocorrem feixes vasculares colaterais.

Ductos secretores foram observados eventualmente dispersos pelo mesofilo, nervura central e margem, sobretudo adjacentes aos feixes vasculares (Figuras 4A - 4G).

\section{DISCUSSÃO}

Os caracteres morfológicos de A. triplinervis referentes ao hábito, forma das folhas e filotaxia estão de acordo com o descrito para o gênero (King \& Robinson, 1970; 1975; 1987; Bremer et al., 1994). No entanto, os tipos branca e roxa diferem pela cor do caule e da nervura das folhas; base foliar; distância dos entrenós; ramificação e presença de brotos foliares que estão em maior quantidade no tipo branca, refletindo na densidade foliar.

Embora se tratando da mesma espécie, as plantas podem responder de modo muito diferente a um dado grau de tensão ambiental, sendo esta resposta inerente ao seu genótipo (Pires \& Gripp, 1988; Castro et al., 2001), fato que justificaria as diferenças externas entre os tipos branca e roxa de A. triplinervis, uma vez que a variação que ocorre

Rev. Bras. PI. Med., Campinas, v.16, n.1, p.62-70, 2014. 


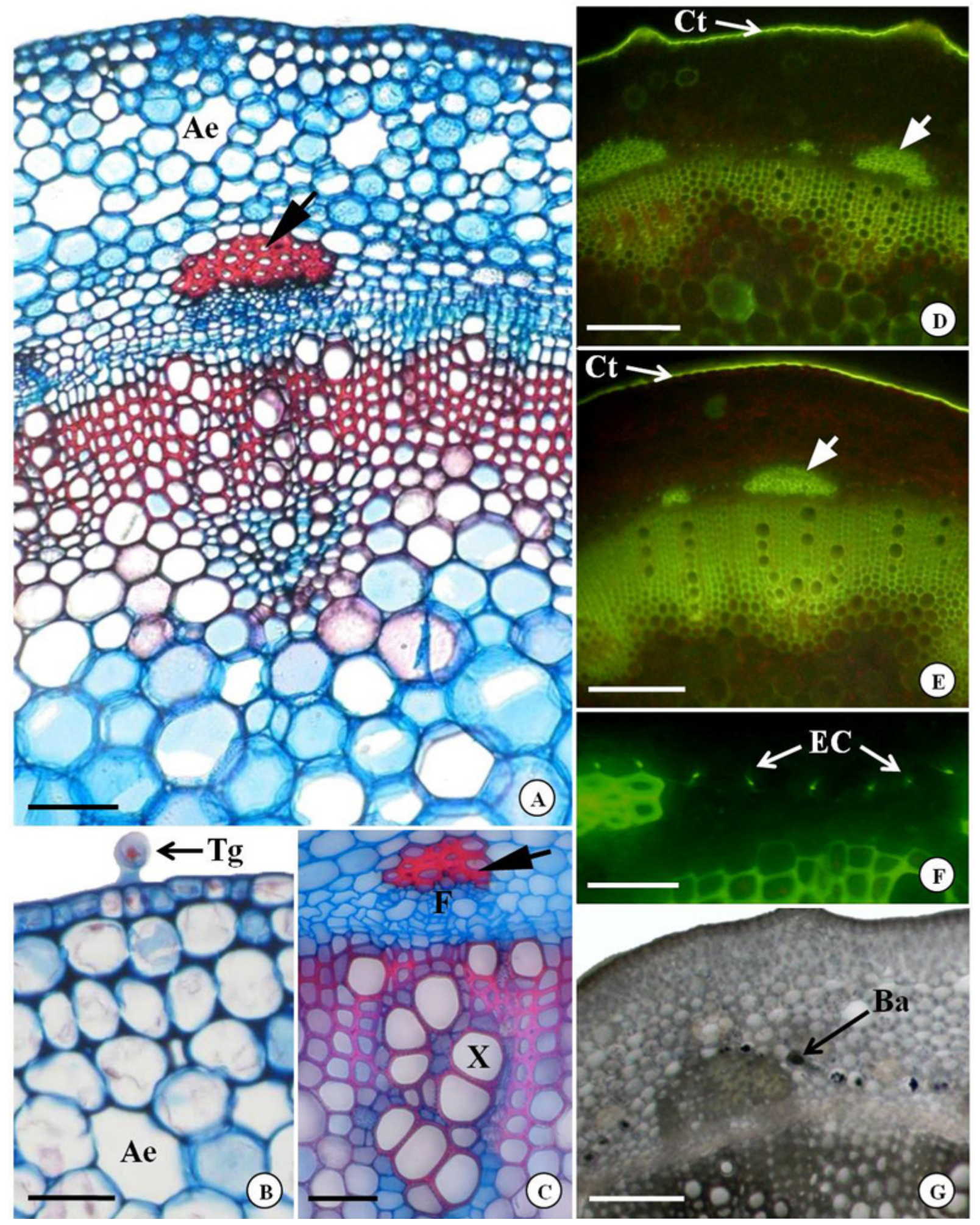

FIGURA 2. Caule em estrutura secundária inicial de A. triplinervis, em secção transversal. Tipos Branca (A, B e E) e Roxa (C, D, F e G). A: Vista geral da organização dos tecidos do córtex, sistema vascular e medula; $B$ : Detalhe do tecido de revestimento, notar tricoma glandular, colênquima angular e aerênquima; C: Detalhe do feixe vascular evidenciando feixe colateral a calota de esclerênquima; D-F: Cutícula, feixes de fibras de esclerênquima, feixes vasculares (D e E) e Estrias de Caspary (F) evidenciados em microscopia de autofluorescência; G: Bainha amilífera. Aerênquima (Ae); Bainha amilífera (Ba); Cutícula (Ct); Córtex (Cx); Estrias de Caspary (EC); Floema $(\mathrm{F})$; Medula (Md); Tricoma glandular (Tg); Xilema $(X)$; Calotas de esclerênquima (setas). Escalas $(A=100 \mu m$; $\mathrm{B}=50 \mu \mathrm{m} ; \mathrm{C}=60 \mu \mathrm{m} ; \mathrm{D}$ e $\mathrm{E}=250 \mu \mathrm{m} ; \mathrm{F}=40 \mu \mathrm{m} ; \mathrm{G}=200 \mu \mathrm{m})$. 


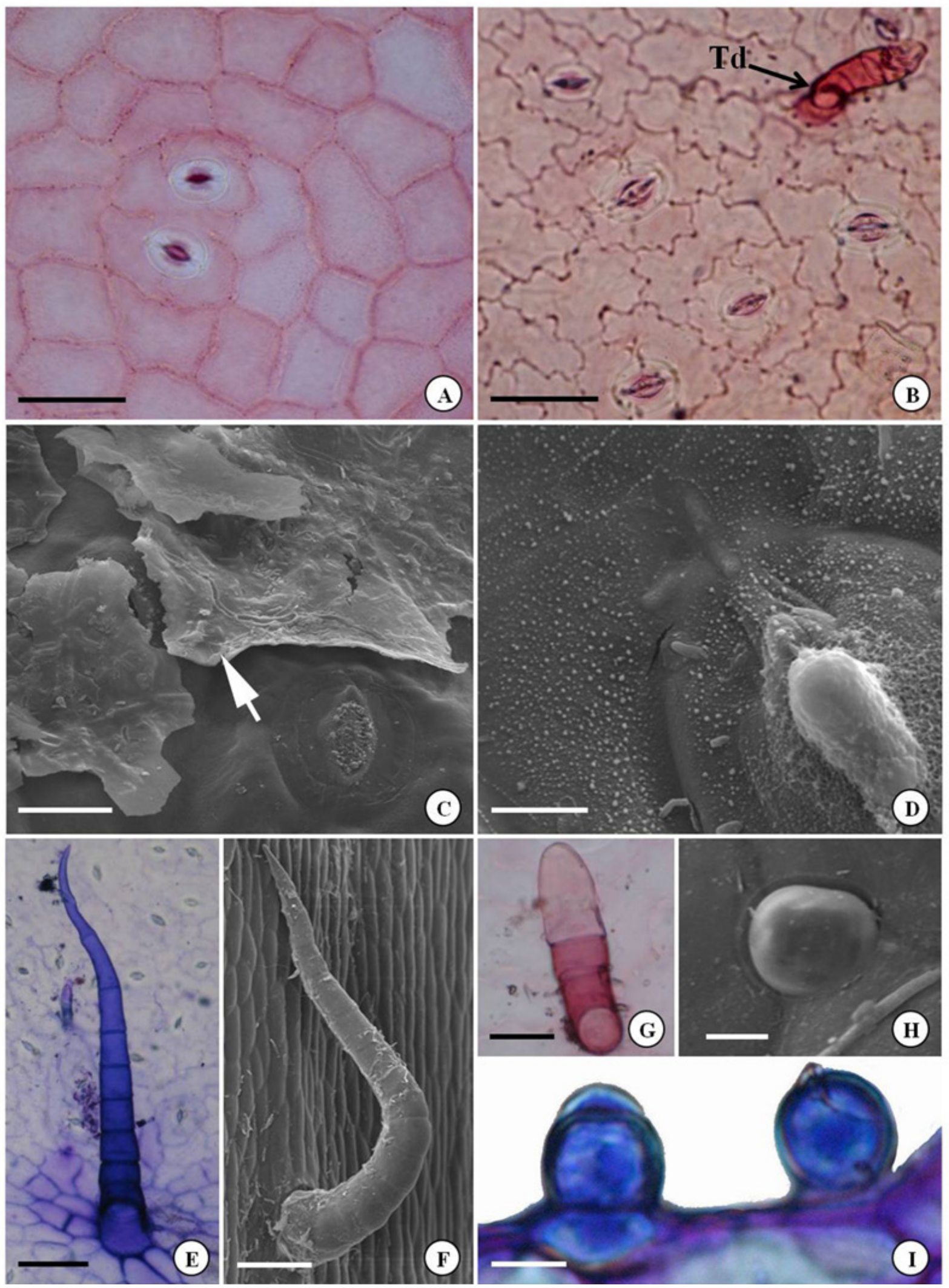

Figura 3. Superfície foliar de A. triplinervis. Tipos Branca (B, C, E, G e I) e Roxa (A, D, F e H). A: Face adaxial; B: Face abaxial; C: Cera em placa contínua na face abaxial (seta); D: Cera granular da face abaxial; E e F: Tricoma tector; G: Tricoma digitiforme; H: Glândula perolada em secção transversal em microscopia eletrônica de varredura; I: Glândulas peroladas em vista transversal. Tricoma digitiforme (Td); Escalas (A e B= 50 $\mu$ m; $C=$ $15 \mu \mathrm{m} ; \mathrm{D}=5 \mu \mathrm{m} ; \mathrm{E}=100 \mu \mathrm{m} ; \mathrm{F}=60 \mu \mathrm{m} ; \mathrm{G}=20 \mu \mathrm{m} ; \mathrm{H}=7,5 \mu \mathrm{m} ; \mathrm{I}=10 \mu \mathrm{m})$. 


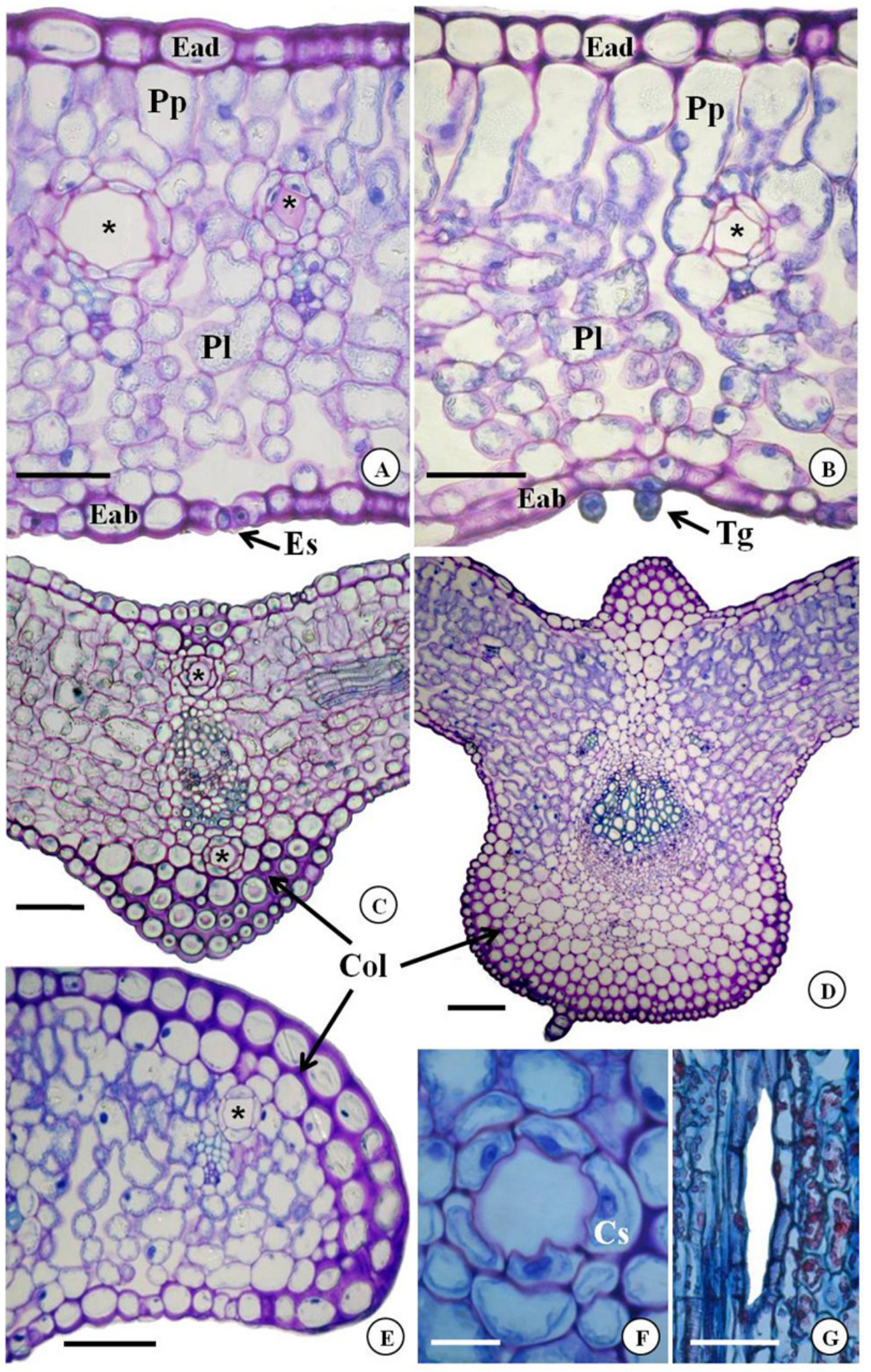

Figura 4- Limbo foliar de A. triplinervis, em secção transversal e longitudinal. Tipos Branca (A, E e F) e Roxa (B, C, D e G) . A e B: Mesofilo dorsiventral, com ductos associados aos feixes vasculares (setas) e glândulas peroladas em depressão da epiderme abaxial (B); C: Região apical; D: Região mediana; E: Margem; F: Ducto delimitado por células secretoras; G: Ducto evidenciando lume alongado. Célula secretora (Cs); Colênquima (Col); Epiderme abaxial (Eab); Epiderme adaxial (Ead); Estômato (Es); Glândula perolada (Gp); Parênquima lacunoso $(\mathrm{Pl})$; Parênquima paliçádico $(\mathrm{Pp})$. Escalas $(\mathrm{A}$ e $\mathrm{B}=60 \mu \mathrm{m} ; \mathrm{C}=200 \mu \mathrm{m} ; \mathrm{D}=300 \mu \mathrm{m} ; \mathrm{E}=60 \mu \mathrm{m} ; \mathrm{F}=$ $20 \mu \mathrm{m} ; \mathrm{G}=50 \mu \mathrm{m})$. 
em populações naturais de plantas é a base da sua resistência perante as pressões do ambiente, sendo a matéria prima da seleção natural (Brown Júnior, 1988).

O caule de $A$. triplinervis exibiu revestimento epidérmico unisseriado persistente, sendo esta uma característica comum para espécies herbáceas de Asteraceae (Metcalfe \& Chalk, 1950) que também foi mencionada para outras espécies medicinais desta família como: Baccharis dracunculifolia DC. (Budel et al., 2004), Elephantopus mollis Kunth (Empinotti \& Duarte, 2008) e Smallanthus sonchifolius (Poepp.) H. Rob. (Duarte et al., 2008).

O tecido colenquimático do tipo angular, evidenciado em $A$. triplinervis, coincide com o encontrado em Calea uniflora Less. (Budel et al., 2006) e Mikania laevigata Sch. Bip. ex Baker (Budel et al., 2009), no entanto, não é um caráter conservativo em Asteraceae, pois podem ocorrer outros tipos como o angular lamelar, encontrado em Acanthospermum australe (Loefl.) Kuntze (Martins et al. 2005), lamelar, observado em Calea longifolia Gardner (Farago et al. 2006) e anelar-angular relatado para Chaptalia nutans (L.) Pol. (Duarte et al. 2007).

A presença de espaços intercelulares amplos, na região cortical, sugere a formação de aerênquima nos indivíduos estudados. Tal característica pode ser decorrente de uma aclimatação às condições úmidas, pois o caule na maioria das plantas desenvolve canais preenchidos com ar, que oferece uma rota de baixa resistência para o oxigênio e outros gases (Taiz \& Zeiger, 2004).

Como observado em A. triplinervis, a presença de endoderme com estrias de Caspary e/ou bainha amilífera também foi destacada para outras Asteraceae como Acanthospermum australe (Loefl.) Kuntze (Martins et al., 2006), Calea longifolia Gardner (Farago et al., 2006), Ageratum fastigiatum (Gardner) R. M. King \& H. Rob. (Vieira et al., 2008) e Elephantopus mollis Kunth (Empinotti \& Duarte, 2008).

Metcalfe \& Chalk (1950) mencionaram a presença de estômatos anomocíticos e tricomas não glandulares e glandulares de diversas morfologias em Asteraceae, podendo localizar-se em ambas as superfícies epidérmicas, sendo que tais caracteres correspondem ao encontrado na folha dos espécimes de Ayapana triplinervis.

Os tricomas, do ponto de vista taxonômico, são importantes para a delimitação de espécies (Theobald et al., 1979). Tricomas tectores como os observados nesse estudo, exercem papel essencial na defesa de plantas, em relação a insetos fitófagos, diminuição da refletância da radiação solar e redução na perda de água (Aoyama \& Labinas, 2005). Com relação aos tricomas glandulares, podem variar quanto à estrutura e secretam diversas substâncias tais como: óleos essenciais, alcaloides e substâncias fenólicas que podem ser usadas na defesa química da planta (Fahn, 1988; Castro et al., 2009).

No que diz respeito ao tricoma glandular formado por célula basal e célula apical esférica, este foi designado por Solereder (1908) como glândula perolada, ocorrendo em órgãos aéreos em espécies de Piper L.. Dessa forma, é relevante destacar a presença de tal estrutura em $A$. triplinervis, tendo em vista que não há registros na literatura sobre sua ocorrência em espécies de Asteraceae, outrossim, a sua presença pode fornecer subsídios à diagnose desta espécie.

Embora para Metcalfe \& Chalk (1950) o mesofilo de Asteraceae seja variável, a dorsiventralidade observada na lâmina foliar de $A$. triplinervis é semelhante à encontada em outras espécies da família (Luque et al., 1999; Martins et al., 2006; Budel et al., 2009).

De acordo com o observado em $A$. triplinervis, a presença de ductos associados aos feixes vasculares, foi destacada para 39 espécies de Asteraceae (Castro et al. 1997); além de Ragonese (1988) em Eupatorium inulaefolium H. B. K.; Milan et al. (2006) em Mikania glomerata Spreng; Duarte et al. (2008) em Smallanthus sonchifolius (Poepp.) H. Rob. e Millani et al. (2010) em Ageratum conyzoides $L$.

Os caracteres morfoanatômicos encontrados nos dois tipos de $A$. triplinervis estão de acordo com os descritos em Asteraceae. Porém, ressalta-se a ocorrência da glândula perolada como uma importante característica a contribuir na identificação dessa planta medicinal, sendo este o primeiro registro para o gênero Ayapana. Ademais, as diferenças encontradas entre os espécimes são relevantes para separá-los em morfotipos.

\section{AGRADECIMENTOS}

Ao Laboratório de Neuroendocrinologia da Universidade Federal do Pará pelo uso do microscópio de fluorescência para a obtenção das fotomicrografias e a CAPES pela bolsa concedida à primeira autora.

\section{REFERÊNCIA}

ALBUQUERQUE, J.M. Plantas medicinais de uso popular. Brasília: Associação brasileira de educação agrícola superior, 1989. 96p.

AOYAMA, E.M.; LABINAS, A.M. Estrutura foliar de Eupatorium maximilianii Schrad. (Asteraceae) e suas Implicações na Herbivoria. Revista Biociências, v.2, n.3-4, p.126-132, 2005.

Rev. Bras. PI. Med., Campinas, v.16, n.1, p.62-70, 2014. 
BERG, M.E. Plantas Medicinais na Amazônia. 3.ed. Belém: Museu Paraense Emílio Goeldi, 2010. 266p.

BOZZOLA, J.J.; RUSSEL, L.D. Eletron microscopy: principles and techniques for biologists. New York: Jones and Barlett Publishers, 1991. 452p.

BREMER, K.; ANDERBERG, A.A.; KARIS, P.O.; LUNDBERG, J. Tribe Eupatorieae. In: Asteraceae Cladistics and classification. Portland: Timber Press, 1994. p.625-680.

BROWN JÚNIOR, K.S. Engenharia ecológica: novas perspectivas de seleção e manejo de plantas medicinais. Acta Amazônica, v.18, n.1-2, p.291-303, 1988.

BUDEL, J.M.; DUARTE, M.R.; SANTOS, C.A.M.; FARAGO, P.V. Morfoanatomia Foliar e Caulinar de Baccharis dracunculifolia DC., Asteraceae. Acta Farmacéutica Bonaerense, v.23, n.4, p.477-483, 2004.

BUDEL, J.M.; DUARTE, M.R.; FARAGO, P.V.; TAKEDA, I.J.M. Caracteres anatômicos de folha e caule de Calea uniflora Less, Asteraceae. Revista Brasileira de Farmacognosia, v.16, n.1, p.53-60, 2006.

BUDEL, J.M.; DUARTE, M.R.; KOSCIUV, I.; MORAIS, T.B.; FERRARI, L.P. Contribuição ao estudo farmacognóstico de Mikania laevigata Sch. Bip. Ex Baker (guaco) visando o controle de qualidade da matéria prima. Revista Brasileira de Farmacognosia, v.19, n.2B, p.545-552, 2009.

CASTRO, M.M.; LEITÃO-FILHO, H.F.; MONTEIRO, W.R. Utilização de estruturas secretoras na identificação dos gêneros de Asteraceae de uma vegetação de cerrado. Revista Brasileira de Botânica, v.20, n.2, p.163-174, 1997.

CASTRO, H.G.; FERREIRA, F.A.; SILVA, D.J.H.; MOSQUIM, P.R. Contribuição ao estudo das plantas medicinais: metabólitos secundários. Visconde do Rio Branco: Editora Suprema, 2001. 104p.

CASTRO, E.M; PEREIRA, F.J.; PAIVA, R. Histologia vegetal: estrutura e função de órgãos vegetativos. Lavras: UFLA, 2009. 234p.

CORREA, M.P. Dicionário das plantas úteis do Brasil e exóticas cultivadas. Rio de Janeiro: Ministério da Agricultura, Instituto Brasileiro de Desenvolvimento Florestal. 1984.

DI STASI, L.C.; HIRUMA-LIMA, C.A.; SANTOS, C.M.; GUIMARÃES, E.M. Asterales Medicinais. In: Di Stasi, L. C.; Hiruma-Lima, C. A. (orgs). Plantas medicinais na Amazônia e na Mata Atlântica. São Paulo: Editora Universidade Estadual Paulista, 2002. p.463-491.

DUARTE, M.R.; SIEBENROK, M.C.N.; EMPINOTTI, C.B. Anatomia comparada de espécies de arnica: Porophyllum ruderale (Jacq.) Cass. e Chaptalia nutans (L.) Pohl. Revista de Ciências Farmacêuticas Básica e Aplicada, v.28, n.2, p.193-201, 2007.

DUARTE, M.R.; WOLF, S.; PAULA, B.G. Smallanthus sonchifolius (Poepp.) H. Rob.(yacón): Identificação microscópica de folha e caule para o controle de qualidade farmacognóstico. Revista Brasileira de Ciências Farmacêuticas, v.44, n.1, p.157-164, 2008.

EMPINOTTI, C.B.; DUARTE, M.R. Estudo anatômico de folha e caule de Elephantopus mollis Kunth (Asteraceae). Revista Brasileira de Farmacognosia, v.18, n.1, p.108-116, 2008.

FAHN, A. Secretory tissues in vascular plants. New Phytologist, v.108, p.229-257, 1988.
FARAGO, P.V.; BUDEL, J.M; DUARTE, M.R.; JURGENSEN, I.; TAKEDA, I.J.M. Anatomia da Folha e do Caule de Calea longifolia (Asteraceae). Acta Farmacéutica Bonaerense, v.25, n.4, p.512-517, 2006.

GERLACH, G. Botaniche Mikrotechnik. Stuttgard: Georg Thieme Verlag, 1969. 344p.

GERRITS, P.O.; SMID, L. A new less toxic polymerization system for the embedding of soft tissues in glycol methacrylate and subsequent preparing of serial sections. Journal of Microscopy, v.132, p.81-85, 1983.

HICKEY, L.J.; ASH, A.; ELLIS, B.; JOHNSON, K.; WILF, P.; WING, S. Manual of Leaf Architecture. Morphological description and categorization of dicotyledonous and net-veined monocotyledonous angiosperms by Leaf Architecture Working Group. Washington, 1999. 65p.

JOHANSEN, D.A. Plant microtechnique. New York: McGraw Hill Book Company, 1940. 523p.

JUDD, W.S.; CAMPBELL, C.S.; KELLOGG, E.A.; STEVENS, P.F.; DONOGHUE, M.J. Sistemática Vegetal: Um Enfoque Filogenético. 3.ed. Porto Alegre: Artmed, 2009. 612p.

KING, R.M.; ROBINSON, H. Studies in the Eupatorieae (Compositae) XX: The genus Ayapana. Phytologia, v.20, n.3, p.210-212, 1970.

KING, R.M.; ROBINSON H. Ayapana. Annals of Missouri Botanical Garden, v. 62, n. 4, p. 888-912, 1975.

KING, R.M.; ROBINSON H. The genera of the Eupatorieae (Asteraceae). Monographs in Systematic Botany from the Missouri Botanical Garden, v. 22, p. 1-581, 1987.

LANS, C. Comparison of plants used for skin and stomach problems in Trinidad and Tobago with Asian ethnomedicine. Journal of Ethnobiology and Ethnomedicine, v. 3, n. 3, 2007.

LILLIE, R.D. Histopathologic tecnic and pratical histochemistry. New York. Mc Graw-Hill Co., 1965. $715 \mathrm{p}$.

LONGUEFOSSE, J.L.; NOSSIN, E. Medical ethnobotany survey in Martinique. Journal of Ethno-Pharmacology, v. 53, p. 117-142, 1996.

LUQUE, R.; MENEZES, N.L.; SEMIR, J. Anatomia foliar de Lychnophora Mart. (Vernonieae: Asteraceae). Plantula, v. 2, n. 3, p. 141-152, 1999.

MAIA, J.G.S.; ZOGHBI, M.G.B.; ANDRADE, E.H.A. Plantas aromáticas na Amazônia e seus óleos essenciais. Belém-Pará. Museu Paraense Emílio Goeldi. Coleção Adolpho Ducke. 2001. 173 p.

MARTINS, A.G.; ROSÁRIO, D.L.; BARROS, M.N.; JARDIM, M.A.G. Levantamento etnobotânico de plantas medicinais, alimentares e tóxicas da Iha do Combu, Município de Belém, estado do Pará, Brasil. Revista Brasileira de Farmácia, v. 86 , n. 1, p. 2130, 2005

MARTINS, L.R.R.; MOURÃO, K.S.M.; ALBIERO, A.L.M.; CORTEZ, D.A.G.; DIAS-FILHO, B.P.; NAKAMURA, C.V. Estudo morfoanatômico preliminar do caule e da folha de Acanthospermum australe (Loefl.) Kuntze (Asteraceae-Heliantheae). Revista Brasileira de Farmacognosia, v. 16, n. 1, p. 42-52, 2006.

METCALFE, C.R.; CHALK, L. Anatomy of the Dicotyledons: leaves, stem and wood in relation to taxonomy with notes on economic uses. 2 ed. Oxford: Clarendon Press. 1950. 1.500 p.

Rev. Bras. PI. Med., Campinas, v.16, n.1, p.62-70, 2014. 
MILAN, P.; HAYASHI, A.H.; APPEZATTO-DA-GLÓRIA, B. Comparative leaf Morphology and Anatomy of Three Asteraceae Species. Brazilian Archives of Biology and Technology, v. 49, n. 1, p. 135-144, 2006.

MILLANI, A.A.; ROSSATO, D.R.; RUBINI-FILHO, C.J.; KOLB, R.M. Análise de crescimento e anatomia foliar da planta medicinal Ageratum conyzoides L. (Asteraceae) cultivada em diferentes substratos. Revista Brasileira de Plantas Medicinais, v. 12, n. 2, p. 127-134, 2010.

O'BRIEN, T.P; FEDER, N.; MCCULLY, M.E. Polychromatic staining of plant cell walls by toluidine blue .O Protoplasma, v. 59, p. 368-373, 1965.

PIRES, M.J.P.; GRIPP, A. Conservação de recursos genéticos de plantas medicinais em banco ativo de germoplasma. Acta Amazônica, v. 18, n. 1-2, p. 6173, 1988.

RAGONESE, A.M. Canales Secretores en los Organos Vegetativos de Eupatorium inulaefolium H.B.K. (Compositae). Acta Farmaceutica Bonaerense, v. 7, n. 3, p. 161-168, 1988.

SCUDELLER, V.V. Diversidade Sociocultural. Etnoconhecimento de plantas de uso medicinal nas comunidades São João do Tupé e Central (Reserva de Desenvolvimento Sustentável do Tupé). In: Santos-Silva, E.N e Scudeller, V.V (orgs). Amazônia Central. Biotupé: Meio Físico, Diversidade Biológica e Sociocultural do Baixo Rio Negro. 2009. p.185-199.
SOLEREDER M. Sistematic anatomy of the dicotyledons. Oxford, Claredon Press. 1908. 1182 p.

SOUZA, N.N.; SILVA, A.F.C.; MARTINS, F.S.; FERREIRA, G.S.; FERREIRA, C.F.A.; RAMOS, F.M.; PEREIRA, R.O. Plantas Medicinais: Etnobotânica na várzea do Mamirauá. Manaus. Instituto de Desenvolvimento Sustentável Mamirauá. SEBRAE. 2003. 218 p.

TAIZ, L.; ZEIGER, E. Fisiologia Vegetal. $3^{a}$ ed. Porto Alegre. Artmed. 2004. 719 p.

THEOBALD, W.L.; KRAHULIK, J.L.; ROLLINS, R.C. Trichome description and classification. In: Metcalfe C.R.; Chalk, L. Anatomy of the dicotiledons. Sistematic anatomy of leaf and steam, with a brief history of the subject. 2 ed. Oxford: Claredon Press, 1979. p. 40-53.

VIEIRA, L.S. Fitoterapia da Amazônia. Manual de Plantas Medicinais $2^{a}$ ed. São Paulo. Editora: Agronômica Ceres LTDA, 1992. 347 p.

VIEIRA, D.V.G.; BARBOSA, M.V.D.; LOPES, B.C.; SOUSA, O.V.; SANTIAGO-FERNANDES, L.D.R.; ESTEVES, R.L.; KAPLAN, M.A.C. Caracterização morfoanatômica de Ageratum fastigiatum (Asteraceae). Revista Brasileira de Farmacognosia, v. 18, p. 769-776, 2008.

VIGNERON, M.; DEPARIS, X.; DEHARO, E.; BOURDY, G. Antimalarial remedies in French Guiana: A Knowledge attitudes and practices study. Journal of EthnoPharmacology, v. 98, p. 351-360, 2005. 